\title{
Men in Early Childhood: A Moral Panic? A research report from a UK University
}

\author{
Mark Cronin $^{1 *}$ \\ ${ }^{1}$ Newman University, Genners Lane, Bartley Green, Birmingham, B32 3NT, England
}

KEYWORDS

Early childhood

Male workers

Moral panic

Othering
ABSTRACT

Significant changes in the role fathers play in their children's care alongside the increased interest shown by teenage boys in working with young children has so far resulted in no noticeable increase in the numbers of men working in Early Childhood in the UK. Previous research has identified how the gendered nature of this workforce presents significant barriers to men's involvement combined with an increasingly dogmatic media discourse which represents men solely as a threat to young children. The research reported in this paper explored the experiences of a group of undergraduate male students in their pursuit of a career working with young children and to what degree the dynamics of being othered had impacted them. It also sought to consider the rhetoric and reality of recent UK government attempts to address the imbalance in the Early Childhood workforce. Thirteen male students from two undergraduate programmes at a UK University were interviewed for this study. The research data identified a number of risk factors which present barriers to men's involvement in Early Childhood such as gender stereotyping, marginalisation or 'othering' of men and negative media discourses. It also identified potential protective factors which enable men's involvement such as supportive family and friends, male role-models and a sense of social responsibility. Broader reflections also identified the significant difference between the UK government rhetoric in support of increasing men's participation in Early Childhood and the reality of the active indifference shown to challenging the barriers to participation driven by political motives which has effectively generated a new 'moral panic' around men working with young children.

* Contact address: t.m.cronin@newman.ac.uk (M. Cronin) 


\section{Introduction}

Since the election of the New Labour government in the UK in 1997 and the subsequent positioning of early childhood in the development of its 'social investment state', this phase of a child's life has become increasingly the focus of attention for policy makers, the media and the general public. As a part of this we have also seen a particular focus on the importance of increasing the involvement of fathers in this period of their children's lives which has been mentioned in numerous policy documents including The Children's Plan (DCSF 2007), Every Parent Matters (DfES 2007), Sure Start Children's Centres: Practice Guidance (DfES 2006) and the National Service Framework for Children, Young People and Maternity Services (DfES and DoH 2004) to name but a few. In parallel and connected to this specific focus there has been an emerging debate regarding the potential impact more men working in the sector may have on both children and their parents. Some of the arguments in favour of an increase in the proportion of men in this field suggest that they have something unique to offer in terms of providing role models to boys (Jensen 1996; Murray 1996). Others argue that the presence of men could only enhance the sector and improve the skills mix in an environment which is female dominated (Ruxton 1996; Moss 2000). However, there have also been suggestions this 'othering' in respect of what men can contribute only serves to illuminate the predominance of specific gender ideologies in this sector which may contribute to barriers to male participation in work with very young children (Cameron 2006). There has also been a significant discourse which has received persistent media attention which questions the motives of men in early childhood and warns of the associated risks. This research considers whether it may be time to consider whether public attitudes towards men in early childhood, fuelled by media discourses are contributing to the emergence of a moral panic in respect of the position of men in early childhood. 


\section{Involvement of Fathers}

There are numerous indicators which suggest that men in the UK are playing an increased role in the care of their children. This is reflected both in terms of an increase in the percentage of single carers who are men from $8 \%$ in 1994 to $11 \%$ in 2005 (ONS 2005) and the numbers of men who are choosing flexible working in order to spend more time with their children (Smeaton and Marsh 2006; Dermott 2008). In a recent survey (Ellison, Barker and Kulasuriya 2009) of 2261 fathers who completed an on-line questionnaire, $21 \%$ of fathers of pre-school children stated that their child was at home with them as part of their weekly childcare arrangements. In the same survey $43 \%$ of fathers of school aged children reported that they provided care before and after-school. This survey also provided evidence that men wanted to spend more time with their children as $42 \%$ felt they spent too little time with their children and over half stated that they would take advantage of proposed changes to paternity entitlements which would facilitate this (Ellison, Barker and Kulasuriya 2009).

As the involvement of men in the care of their children increases, questions are emerging about how well men engage with services which are designed to support children in early childhood. Currently it seems that much more could be done to engage with men as a survey of 1400 early years settings in the UK conducted by Kahn (2005) found that only $40 \%$ of these managed to engage with fathers and that in $60 \%$ of cases they had not managed to engage with fathers at all. In terms of activities designed to engage with fathers, $45 \%$ of the settings had arranged one-off events to attempt to attract fathers but in only $9 \%$ of settings was there any on-going commitment to father specific provisions. In his conclusions Kahn (2005) suggested that the presence of males could help fathers feel more relaxed in a predominantly female environment and that previous research had suggested that fathers may perceive early years settings to be female only spaces and find them intimidating (Lloyd, O'Brien and Lewis 2003). This research is supported by the more recent work of Page, Whitting and Mclean (2008) who on behalf of the Department for Children, Schools and Families 
(DCSF) approached every Local Authority in England to ascertain the level of support offered to fathers. The research concluded that:

'Local Authorities did not take a strategic lead on supporting fathers' and that 'any local practice had generally developed sporadically and was the result of specific managers and practitioners taking an interest in the issue' (Page, Whitting \& Mclean 2008, 6).

This research found that there was a lack of skills and training amongst managers and practitioners to help them understand the needs of fathers and engage with them. They also concluded that as the workforce was predominantly female it may lead fathers to feel that the service was not for them and recommended that Local Authorities review how family services could recruit a higher proportion of male practitioners (Page, Whitting and Mclean 2008).

\section{Men in Early Childhood}

A report by the Equal Opportunities Commission on the position of men in the childcare workforce (Rolfe 2005) concluded that based on all available sources of data men constituted around 2-3\% of the childcare workforce. Also that in spite of both national and local recruitment campaigns aimed at men, this figure had remained steady over the previous decade. This is concerning in light of research conducted by the Children's Workforce Development Council (2009) where over half of the parents surveyed said they wished the workforce better reflected the gender mix. In the same study $59 \%$ of these parents reported that their current childcare provision did not have a male worker (cited in Watson 2009). In fact these sentiments have been expressed in previous studies exploring the public's views on the involvement of men in childcare settings. The Thomas Coram Research Unit conducted a survey in nurseries that employed at least one man and found that $80 \%$ of parents were in favour of male workers (Cameron, Moss and Owen 1999) and The Daycare Trust research (2002) found that 77\% were in favour of more men working in childcare. 
It is well documented that men may find it difficult to see childcare as a career option as it is equated with mothering, has low pay/poor working conditions and low status (Cameron, Moss and Owen 1999). It is also suggested that they may be subject to negative reactions from those feeling that childcare is not a 'normal' job for a man, being questioned regarding their motives and suspected of having perverse sexual intentions (Rolfe 2005). Owen (2003) suggests that high levels of media attention given to paedophiles may have heightened these concerns among some parents. In addition to this, there is evidence to suggest that men who did enter the workforce become aware of the omnipresence of female-defined values and that the 'female way' was considered the norm (Cameron 2006) which may also contribute to the consistently low level of male participation in this workforce. These social attitudes are rooted in the gendered nature of the childcare workforce which has been discussed in a number of earlier studies (Cameron 2006; Rolfe 2006; Murray 1996). Gender is understood to be a social construct involving the process of assigning certain characteristics to individuals based on their sex according to social context (Lorber and Farrell 1991). In the field of childcare this has been manifest in the ways in which a woman's presence is to be expected as an extension of 'mothering' (Penn and McQuail 1997) as well as her possession of the necessary ability to be empathetic, caring and sensitive. Conversely, by locating childcare as 'women's work' (Rolfe 2006), men are not viewed to be natural candidates and questions are raised about their possession of these fundamental attributes. Furthermore, they may be expected to behave in ways which reflect more stereotypical 'male' characteristics such as undertaking practical tasks i.e. 'changing light-bulbs' or outdoor play (Cameron 2006). This process of identifying the ways in which men are 'different' or 'other' draws attention to the ways in which they do not do not conform to the 'female way'. It can also result in the process of 'othering' (Sumison 2000) which is where the 'other' (in this case a male worker) as a consequence of their difference can be marginalised and their power diminished which was observed by Cameron (2006) in her study where for example the male 
childcare workers possibilities to use physical comfort with the children was limited. This was also noted in the work of Sargent (2005) who found that comforting children was the domain of women staff, presumably because as opposed to their male counterparts the women possessed the necessary skills and attributes.

However, despite these barriers there is research to suggest that both men and boys are interested in working with children. Research conducted by MORI for the Daycare Trust found that $27 \%$ of men surveyed would consider working in the childcare sector (Daycare Trust 2002), a figure which is not reflected in the numbers of men in the workforce. This level of interest was also mirrored in research commissioned by the Equal Opportunities Commission with 14-15 year old boys where $25 \%$ of boys agreed that a career in caring sounded interesting (Fuller, Beck and Unwin 2005) and a further $12.5 \%$ of boys of the same ages in a separate survey expressed an interest in working with children (Cook 2005).

Therefore, the intention of this research was to explore the incongruence between the increased involvement of men in the care of children and the consistently low levels of male employment in the childcare sector in spite of the comparatively high levels of expressed interest in this career by men and boys.

\section{Moral Panic}

It was Stanley Cohen whose book Folk Devils and Moral Panics first published in 1972 (Cohen 2011) brought the term 'moral panic' into widespread discussion. Cohen later described the characteristics of a moral panic as 'a condition, episode, person or group of persons (who) become defined as a threat to societal values and interests' $(1987,9)$. It is a phrase which has subsequently been used to great effect to illuminate public discourses which seek to protect the 'innocence' of childhood and tackle the perceived risks to this. The idea of children's 'natural innocence' is a direct reference to the enduring 'romanticisation' which has become central to the western conceptualisation of childhood influenced by the work of Jean Jacques 
Rousseau in his book Emile (Gabriel 2010). This social construction suggests that children are born innocent and are in need of protection from the risks posed by the adult world which would interfere with their 'natural' development. In the case of this investigation the focus of concern being the potential sexualisation of children. For Cohen these 'moral panics' were defined by the ways in which both the media and those with political power define a social group as a threat to perceived social values. It is proposed therefore in this research that a combination of partisan media stories which cast men solely as a potential threat to young children with particular reference to their predatory sexual interest (Owen 2003; Rolfe 2005) alongside the lack of significant political will to address the on-going barriers to male participation in early childhood create the conditions necessary for us to consider the emergence of a 'moral panic'.

\section{Research Aims and Objectives}

This research aimed to explore the factors which could potentially prevent men from entering the sector as well as those which motivate men to want to work with young children. The research employed a well established tool for analysis based on the Resilience model as outlined by Rutter (1987) and subsequently adapted. Therefore, it considered the interplay between the risk/stress factors or barriers which may deter or impede men from entering the childcare sector as well as considering the protective factors or supports which may motivate men to take this step. In pursuit of this the first research question was 'What factors act as a barrier to men working with young children?' and explored factors which may prevent men from working with children and considered both the personal and public perceptions which are prevalent and which may contribute to the low levels of male employment in this sector. The second research question was 'What factors motivate men to work with young children?' and explored factors which may have provided the inspiration or motivation to work with young children in spite of any associated negative personal and public perceptions. The final 
research question was 'What attempts have been made to encourage more men to work with young children?' and explored any attempts made to encourage more men to work with children in terms of the approaches taken and the impact of these on the participants.

This research explored the hypothesis that limited use has been made of the available potential for men to enter the childcare workforce by ignoring the motivators which could facilitate the desired increase and not adequately tackling the barriers to participation.

\section{Methodology}

The research utilised an evaluative case study approach incorporating a mainly qualitative paradigm. This approach was adopted as it allowed the researcher to engage in 'an empirical inquiry that investigates a contemporary phenomenon within its real life context' (Yin 1994, 23). In order to explore the factors which have influenced these men it was essential that the study focused on a naturally occurring process whereby the men had chosen to move towards working with young children, in this case via specialised learning in Higher Education. Greig, Taylor and Mackay (2007, 145) define a case study as 'an investigation of an individual, a family, a group, an institution, a community or even a resource, programme or intervention' and in this research the 'case' referred to the groups of male students at Newman University. This methodology also provided the opportunity to explore one aspect of a problem in some depth (Bell 2005) thereby lending itself well to the collection of the qualitative data required to examine the specific nature of potential barriers/motivators which may have influenced men's decisions to consider working with young children. It is acknowledged that there may be obvious limits to the generalisability of the findings associated with the case study approach (Gilbert 2008). However, the intention was that this approach be employed as an instrumental case study and as such it explored a phenomenon that may have wider interest and as such the findings could be generalised across to similar 
cases/settings (Mukherji and Albon 2010). The research employed the semistructured interview as a method to acquire the necessary data to address the research questions. This method allowed the participants to develop their own narrative whilst ensuring that the key themes important to the research questions were addressed.

\section{Participants}

Participants included male undergraduate students from two BA Honours programmes at a UK University (BA Hons Early Childhood Education and Care \& BA Hons Working with Children, Young People and Families). As such a purposive sampling strategy was employed as all of the participants had made a decision to engage in a learning process which might result in them working with young children. At the time of the research 460 students in total were registered on these programmes of which 15 were male. Informed consent was secured from 13 of the 15 male students and as such 13 semi-structured interviews were carried out. It is significant to note that the participants fell into two sub-groups based on their ages and routes to Higher Education. The first sub-group comprised of seven younger men (aged 20-24 years old) who had little work experience and had progressed to higher education as part of an on-going educational career. The second subgroup comprised of six older men (aged 29-47 years old) who had significant work experience and had later returned to higher education.

\section{Analysis}

\section{Barriers to male participation}

For all but one of the participants (12) in the sample, gender stereotyping was identified as influential in preventing men considering this as a career option and they made clear reference to the assumption that this considered to be women's and not men's work. One man stated 'At my placement there was a couple of females that I wouldn't say took a dislike to me but I had the 
impression, you know, why are you here go out and get a man's job'. These men went on to make reference to the way women are always portrayed as children's carers in the media and that this vocation was seen as an extension of a woman's traditional role in the family. They also made reference to the idea that women are seen as more caring/nurturing/empathetic and at times the men in this sample appeared to have accepted this idea to be generally true. Three of the men suggested that the lack of men would only serve to reinforce established gender stereotypes with young boys in these settings being aware of the absence of men. Significantly, just over half of the men (7) reported that these attitudes had caused them to either experience self-doubt or be the subject of scrutiny from either family/friends or service users. Two of these men commented on their masculinity coming into question with one reporting 'can't do a trade so he works with kids, doesn't want a real job so he works with kids, not able to function in the real world so he wants to dominate kids...its always on my mind'. Two of the men made reference to having their motives questioned by family and friends with one other explaining that his family never talk about his profession 'I can see on their faces that they think it is a strange profession to choose, they are all working in factories'. Three of the men explain that these attitudes result in them not feeling wanted in this profession with one man stating 'I tried to get some nannying work but most of them wanted a woman to look after their child, makes you feel like no-one wants ya'. One man reported being directly challenged by one parent who asked 'why on earth as a man have you chosen to do this?'

All but one of the men (12) stated that they had been treated differently in their work with children due to their gender. Four of the men reported that they had felt marginalised by colleagues with one stating 'female practitioners can try to make you feel inferior, what does he know about childcare, what does he know about early development, how will he meet the needs'. This was mirrored in the comments made by another man who stated 'you feel like an outsider, marginalised and as though your views don't hold much weight, because I couldn't have children that I didn't 
fully understand'. He went on to state 'at one place I did feel shut out. It was like I was invading their territory'. Three of the other men spoke about the difficulties they experienced socialising with colleagues in settings and that the absence of common interests could present some barriers to feeling settled. Two of the men made reference again to the attitudes of parents towards their presence in such settings. One man made reference to being subject to specific gender stereotypes 'you might get asked to do things, you're like the handy man, they kind of dump things on you'. Significantly two of the men made reference to the attitudes of women they had come across in their studies with one stating 'I found that on my course as well there were slights and little digs about the guys. About men being slow, about men being unreliable, about men being after only one thing'. The other man made reference to feeling like there were higher expectations of his contributions in lectures and that he felt under the spotlight.

Also for the majority (7) of the men in this sample they felt that the dominance of the discourse around childcare being a woman's domain has resulted in the presence of men in these vocations being viewed with suspicion in society. For one man he reported 'Even when I do football at the weekend, it took me six months to speak to the parents properly, they weren't sure what to make of me. It was a bit daunting because I' $m$ out there with the children and I think if I do one thing wrong then I think they're gonna be onto me'. The participants reported that men's motives are often questioned in terms of being sexually interested in the children and this could put men off entering the profession. It was also noted that the predominance of media portrayals of men as child molesters, not as nurturing/caring, plays a significant role in this discourse. The men also identified that questions about their sexuality and assumptions that they were homosexual could present a barrier. One man stated 'Generally the stereotype is you've got to be in touch with your feminine side to be a children and young people's worker, a homosexual or have paedophilia tendencies'. Other issues identified as a barrier were the low pay with one man stated 'there is a discourse that women don't need to get paid a lot for 
being caring as they care naturally but men who are not naturally caring need to work hard to acquire these skills and therefore need to be paid more'.

\section{Motivating factors}

It is significant to identify here that for most (9) of the men in this sample working with children was not their first choice. In fact only four reported that they had started their working lives with intentions to work with children. Of the other nine men, five had started their working lives in Industry, two had worked in Business environments and of the other two, one had aspired to become a firefighter and the other to enter the armed forces.

For the majority of these men, they had never considered working with children and their decision to pursue this career had been influenced by advice from family and friends. Eight of the men reported being advised by close family or friends that they had particular skills/abilities which would be well suited to working with children. For one man it was his church Pastor, he stated 'he saw something in me that I didn't necessarily see in myself, I was just doing what I was doing'. The other five men reported different sources of motivation for pursuing this career with three of these being motivated by a sense of social responsibility, one by the desire to have variety in their work lives and one an unfulfilled realisation of their known ability to work with children.

It is interesting to note here some significant differences between the older and younger sub-groups in the sample. All but one of the older subgroup reported having started their working lives on a different career path. The reasons they offered, even when they acknowledged they were aware at a young age of their ability/skills to work with children, was the need to earn good money or enter a more masculine vocation. For the men in the younger sub-group just over half (four) reported having started their working lives on a different career path. Of the other three only one clearly stated a commitment to working with children. One had been heavily 
guided by his mother and sister (who were both teachers) and the other was motivated by the desire for variety in his working life.

The theme around the impact of others to inspire these men to pursue this career appears to have been significant for the participants. Six of the men reported being encouraged by others to pursue this career with responses indicating that it was feedback from others which had resulted in this career even being considered, one man stated 'My first thoughts about working with children came as a result of my Business Studies teacher suggesting I sit in a nursery class as they'd noticed I was interested in talking about kids. Before this I'd never really considered it, thought I'd work in an office or get a trade like building or plastering, I was fifteen'. Five of the men made specific reference to the lasting impact a male teacher/s had had on them in their own school experience, one man who stated 'Another factor is when I was little I always remember my male teachers sticking out, I remember them being funny or entertaining' whilst for another 'I remember in year three we had a male teacher and I never forgot as he was the only male teacher until year 6...I always thought it was fantastic...he just kept us engaged the whole time... with this teacher it was something different'. Other key themes were the desire to make a difference to the lives of children (3) or the impact/reactions the men had had on children and young people they were working with (2). One of the men made reference to the significance of him being a father and seeing his own children develop.

In terms of a personal motivation over half of the men (7) reported that they felt they had something to offer and made reference to wanting to make a difference in children's lives, giving something back and being a role model. Significantly, all of the men in the older sample made reference to feeling they had something to offer but only one from the younger sample. This may reflect their relative levels of self-confidence or understanding of the nature of the work. Just under half of the men (6) reported that they enjoyed this type of work and this was their motivation for pursuing this career. Five of the men made reference to the influence of male role models, 
for whom three wanted to offer themselves as role models and for the other two they themselves had taken inspiration from their own male role models. For two of these five men it was very important to have men in the workforce as they felt single sex environments in any profession were not healthy. For one man 'one of the fundamental parts for me is I believe that the input of a male is very important for both male and female children'. For another 'undoubtedly some children will relate to men differently than they do to women so its potentially at the child's advantage to have a diverse workforce'.

\section{Attempts to encourage male participation}

The majority of the men in the sample (7) reported that they were aware of no specific attempts to encourage more men to work with young children. Of the other six men, two had seen items in the media drawing attention to the lack of men working with young children with the remaining four men making reference to specific campaigns to encourage more men to work as Primary School Teachers.

\section{Discussion}

Consideration of the findings in relation to the three original research questions identifies some clear themes for the participants as well as wider implications for the workforce. In relation to the first research question 'What factors act as a barrier to men working with young children?' it was apparent that the issue of gender stereotyping was central for the participants. They reported routinely having their capabilities as men coming into question from both their female colleagues and parents which manifested itself in two main ways. Either in the form of a discourse which suggested that they did not possess the same competence in relation to being caring, nurturing and empathetic or understanding of children's needs as their female colleagues with the common assumption being that these 
required skills and abilities were more readily available to women as this type of work is merely an extension of motherhood, which supports the previous work of Cameron (2006). Or in the belief that working with young children was not considered 'real man's work' and therefore they should either acquire such work or the attributes required to become a 'real man'. Significantly for some of the men, the later of these two gender stereotypes was also represented in the views of their family and close friends which indicates the power of these discourses. The men also reported that their motivation for wanting to work with young children had been routinely questioned. They identified the significance of media portrayals of men as child molesters as noted in the work of Rolfe (2005) which has led to them being viewed with suspicion by parents and female colleagues. They also reported that their sexuality had been called into question with assumptions being made that they were homosexual. Overall, it appears that these men were subject to the process of being 'othered' as suggested by Sumison (2000) which separated and labelled them as different and less able than their female colleagues. Of course the process of othering requires the exercise of power, an issue which will be returned to later in this discussion when considering the role of the state in the emergence of a 'moral panic' (Cohen 2011) around the position of men in early childhood. It was also significant that the men made reference to the low pay and associated low status assigned to working with young children as a barrier as noted earlier by Cameron, Moss and Owen (1999) which again may be connected to the exercise of state power.

In respect of the second research question 'What factors motivate men to work with young children?' once again the impact of gender stereotypes was evident. The majority of the men stated that working with young children was not their first choice of career paths, even when they had the necessary skills and abilities to do this type of work. The men reported that they had felt the pressure to get jobs that were more masculine (working in Industry/Business environments) and provided better financial rewards. There were some significant differences between the older and young sub- 
group in this respect, with the younger men much more likely to have started their careers with an intention to work with young children. However, interestingly for those who did make an early decision to enter this workforce, only one expressed a clear desire to work with young children. For the majority of these men, the advice of family and friends had been pivotal in their decision to consider a career working with young children. It is clear from the findings that these men who had the potential to make a positive contribution to working with young children had either been reluctant or actively discouraged from this career path and required external validation to make this career choice. In terms of personal motivation the men were largely influenced by a sense of social responsibility and wanted to make a difference in the lives of young children. They felt it was important that men were present in the lives of young children. Significantly, for many of these men they reported the lasting impact a male teacher had had on their early lives which they felt had contributed to their subsequent motivation to work with young children. It is interesting to note that although half (3) of the men in the older sub-group were fathers when they decided to pursue a career in Early Childhood, only one of them cited this as a motivating factor. As noted earlier by Kahn (2005) childcare settings have failed to significantly engage with fathers which may have left them feeling that early years settings are female only spaces (Lloyd, O'Brien and Lewis 2003). Subsequent research by Page, Whitting and McLean (2008) indicated that childcare settings being predominantly female may lead fathers to feel that the service was not for them and recommended that Local Authorities review how family services could recruit a higher proportion of male practitioners. In light of the significant increase in the interest and involvement of fathers in the care of their children (Smeaton and Marsh 2006; Dermott 2008; Ellison, Barker and Kulasuriya 2009) it seems that a considerable opportunity to capitalise on what fathers could bring to the workforce is being missed. 
In relation to the third and final research question 'What attempts have been made to encourage more men to work with young children?' it was evident that these men had not been significantly affected by any particular campaigns to redress the gender imbalance in the workforce. Most of the men stated that they were aware of no attempts to encourage more men to work with young children. Some of the men did reflect on news stories discussing the absence of men and others were aware of campaigns to recruit more male teachers. However, it is clear that the support and encouragement of family and friends was at the heart of their decisions to pursue this career rather than any media campaigns. In her comprehensive review of Men in Childcare (2005) Heather Rolfe concludes that initiatives to increase the employment of men in this sector have come largely from the work of charitable organisations and that employers see the responsibility to make improvements in this area as lying with Government. It is evident that the men in this research have not been exposed to any co-ordinated state intervention to address this issue which reinforces the assertion that the state is not committed to increasing the prevalence of male practitioners in Early Childhood services.

\section{Conclusion}

It is almost certainly the case that the men in this study had demonstrated considerable resilience in their pursuit of a career working with young children in face of significant gender stereotypes which either imply that men do not possess the necessary attributes/skills or that they present a risk to young children. It is also true that the power of these ideas stood in the way of these men (particularly the older sub-group) realising their potential contributions to the workforce, not to mention those men (outside of this sample) who have been persuaded to pursue more masculine careers. It is interesting to note that the younger men in this study were more inclined to see the potential for a career working with young children than the older men which does suggest possible changes in gender roles as identified in the 
work of the Equal Opportunities Commission (Fuller, Beck and Unwin 2005) and Cook (2005). However, as noted by Rolfe (2005) despite national and local recruitment campaigns an increased level of interest from young men does not seem to have translated into a greater proportion of male practitioners. The answers to this incongruence may lie in the increasingly political significance of early childhood provision.

Since their election in 1997, the New Labour government was driven by a new ideology referred to as the 'Third Way' which resulted in 'social policy which focused on social investment, with the primary aim of building an individual's capacity to engage in the labour market' (Cronin and Brotherton 2013, 37). This 'social investment state' identified early childhood as a unique place to begin building this capacity and subsequently invested in increasing levels of state subsidised childcare provisions as well as introducing an Early Years Foundation Stage curriculum (DfES 2007). This New Labour project has been adopted and developed by the current Coalition government who also see the potential to invest in early childhood to increase subsequent economic activity. It is however significant that despite the rhetoric around the professionalization of the early childhood workforce, it continues to be characterised by low paid/low status work as indicated by the average hourly pay rate for non-supervisory/managerial staff being only marginally higher than the governments national minimum wage (the minimum wage being a measure of minimum financial income set by the UK government to which all workers are entitled by law).

It is clear that these successive governments have had a vested interest in keeping the average pay as low as possible in order to meet the demands of the 'social investment state' which requires the exercise of budgetary constraint. Therefore in light of the growing concerns around the potential risks posed by men working with young children, propagated by partisan media stories (which was clearly evident in the experience of the men in this study) alongside the apparent vested interest recent UK governments have had in restricting pay levels in the sector (which presents significant problems for men) and their subsequent reluctance to address the gender 
imbalance in this workforce, it can be argued that the conditions required to constitute a 'moral panic' have been met. The dangers posed by men to the innocence of childhood projected by a particular media discourse which suggest that men have predatory sexual intentions have been passively facilitated by state collusion in order to meet the political needs of the 'social investment state'. In other words the state's requirement to exercise budgetary controls in respect of welfare services alongside the growing political expectation of an expansion of early childhood education and care provision has resulted in active apathy towards improving the pay and conditions of this workforce. Therefore a media discourse which discourages men's involvement in early childhood has enabled UK governments to avoid pressure to improve pay and conditions in this workforce.

This growing concern around men in early childhood is undoubtedly contributing to the relative absence of men in early childhood in the UK (also evident in other European countries - Cameron et al. 2003) despite a broader pattern of their increased involvement in family life. There is clearly scope for further investigation of the challenges facing men who enter the childcare workforce in respect of a broader consideration of the issues raised in this research. However, it appears that the only hope for a workforce which continues to benefit from the involvement of men committed to social responsibility and meeting the needs of young children is those family and friends who recognise their skills and abilities and encourage them to pursue such a career.

\section{Acknowledgements}

Many thanks to those men who took part in this research for providing a full and frank insight into their experience of pursuing a vocation in Early Childhood without which this research would not have been possible. 


\section{References}

Bell, Judith. 2005. Doing Your Research Project, a Guide for First-Time Researchers in Education, Health and Social Science. Maidenhead: Open University Press.

Cameron, Claire. 2006. "Men in the Nursery Revisited: issues of male workers and professionalism." Contemporary Issues in Early Childhood 7 (1): 68-79.

Cameron, Claire, Peter Moss and Charlie Owen. 1999. Men in the Nursery: gender and caring work. London: Paul Chapman Publishing.

Cameron, Claire, Mano Candapapa, Ann Mooney, Susan McQuail, Peter Moss and Pat Petrie. 2003. Early Years and Childcare International Evidence Project. DfES/SureStart Research Report.

Cohen, Stanley. 1987. Folk Devils and Moral Panics, Abingdon: Routledge.

Cohen, Stanley. 2011. Folk Devils and Moral Panics, Abingdon: Routledge.

Cook, Claire. 2005. “It's not what men do': investigating the reasons for the low number of men in the early childhood workforce." In Perspectives on early childhood education: essays in contemporary research, edited by Katherine M. Hirst and Cathy Nutbrown, 55-62. Stoke-on-Trent: Trentham Books.

Cronin, Mark and Graham Brotherton. 2013. "The legal and policy context." In Working with Vulnerable Children, Young People and Families, edited by Graham Brotherton and Mark Cronin, 35-48. Oxon: Routledge.

Daycare Trust. 2002. Men and Childcare. www.ipsos-mori.com.

Department for Children, Schools and Families. 2007. The Children's Plan: Building Brighter Futures. London: HMSO.

Department for Education and Skills. 2007. Every Parent Matters. London: HMSO.

Department for Education and Skills. 2006. Sure Start Children's Centre Practice Guidance. Nottingham: DfES Publications.

Department for Education and Skills. 2007. Practice Guidance for the Early Years Foundation Stage: Setting the Standards for Learning, Development, and Care for Children from Birth to Five. Nottingham: DfES Publications.

Department of Health and Department for Education and Skills (DH/DfES). 2004. National Service Framework for Children, Young People and Maternity Services: Core Standards. London: Department of Health.

Dermott, Esther. 2008. Intimate fatherhood: A sociological analysis. London: Routledge. 
Ellison, Gavin, Andy Barker and Tia Kulasuriya. 2009. Work and Care: a study of modern parents. Manchester: Equality and Human Rights Commission. Research Report 15.

Fuller, Alison, Vanessa Beck and Lorna Unwin. 2005. Employers, young people and gender segregation. Manchester: Equal Opportunities Commission.

Gabriel, Norman. 2010. "Adult's concepts of childhood." In Early Childhood Studies: an introduction to the study of childrens' worlds and children's lives, edited by Rod Parker-Rees and Caroline Leeson, 137-151. Exeter: Learning Matters.

Gilbert, Nigel. 2008. Research Social Life. London: Sage.

Greig, Anne D., Jayne Taylor and Tommy MacKay. 2007. Doing Research with Children. London: Sage.

Jensen, Jytte Juul. 1996. Men as Workers in Childcare Services. Brussels: European Commission Network on Childcare.

Kahn, Tim. 2005. Fathers' Involvement in Early Years Settings: Findings from Research. Pre-School Learning Alliance.

Lloyd, Nigel, Margaret O'Brien and Charlie Lewis. 2003. Fathers in Sure Start Local Programmes: National Evaluation Summary. London: National Evaluation of Sure Start.

Lorber, Judith and Susan A. Farrell (eds.). 1991. The Social Construction of Gender. Newbury Park: Sage.

Moss, Peter. 2000. Workforce Issues in Early Childhood Education and Care. New York: Institute for Child and Family Policy, Columbia University.

Mukherji, Penny and Deborah Albon. 2010. Research Methods in Early Childhood: An Introductory Guide. London: Sage.

Murray, Susan B. 1996. "'We all love Charles' - Men in childcare and the social construction of gender." Gender and Society 10 (4): 368-385.

Owen, Charlie. 2003. "Men in the Nursery." In Rethinking Children's Care, edited by Julia Brannen and Peter Moss, 99-113. Buckingham: Open University Press.

Page, James, Gill Whitting and Carl Mclean. 2008. A Review of How Fathers Can be Better Recognised and Supported Through DCSF Policy. Nottingham: DCSF. Research Report No DCSF-RR040.

Penn, Helen and Susan McQuail. 1997. Childcare as a Gendered Occupation, Department for Education and Employment Research Report 23.

Rolfe, Heather. 2005. Men in Childcare. Manchester: Equal Opportunities Commission. Working Paper Series No. 35. 
Rolfe, Heather. 2006. "Where are the men? Gender Segregation in the Childcare and Early Years Sector." National Institute Economic Review 195: 103-117.

Rutter, Michael. 1987. "Psychosocial resilience and protective mechanisms." American Journal of Orthopsychiatry 57 (3): 316-331.

Ruxton, Sandy. 1996. Children in Europe. NCH Action for Children.

Sargent, Paul. 2005. "The Gendering of Men in Early Childhood Education." Sex Roles 52 (3/4): 251-259.

Smeaton, Deborah and Alan Marsh. 2006. Maternity and paternity rights and benefits: survey of parents 2005. London: Policy Studies Institute, Department for Work and Pensions/Department for Trade and Industry.

Sumison, Jennifer. 2000. "Negotiating Otherness: a male early childhood worker's gender positioning." International Journal of Early Years Education 8 (2): 129-140.

Watson, Ross. 2009. "More men needed in childcare jobs." Children and Young People Now, 20 January 2009.

Yin, Robert K. 1994. Case Study research: design and methods. Thousand Oaks: Sage. 